\title{
NMR spectroscopy and ion pairing: Measuring and understanding how ions interact ${ }^{\star}$
}

\author{
Paul S. Pregosin \\ Laboratory of Inorganic Chemistry, ETHZ Hönggerberg, 8093 Zürich, Switzerland \\ Abstract: Pulsed gradient spin-echo (PGSE) diffusion and Overhauser NMR data together \\ with density functional theory (DFT) calculations afford a qualitative estimation of the \\ amount of ion pairing, as well as insight into the structures of a variety of inorganic, organic, \\ and organometallic salts.
}

Keywords: NMR spectroscopy; diffusion data; ion-pairing NOEs; charge distribution; salt structure.

\section{INTRODUCTION}

There is a continuing, indeed growing, interest in measuring diffusion constants via NMR spectroscopy $[1,2]$. Specifically, one finds a substantial, multinuclear $\left({ }^{1} \mathrm{H},{ }^{7} \mathrm{Li},{ }^{19} \mathrm{~F},{ }^{31} \mathrm{P},{ }^{195} \mathrm{Pt}\right)$ literature concerned with the use of pulsed field gradient NMR methods to measure diffusion constants [3-6], and the subject has been reviewed several times [7,8]. In the classical pulsed field gradient spin-echo (PGSE), Fig. 1, transverse magnetization is generated by the initial $90^{\circ}$ pulse that, in the absence of field gradients, dephases due to chemical shift, hetero- and homonuclear coupling evolution, and spin-spin $\left(T_{2}\right)$ relaxation. After application of an intermediate $180^{\circ}$ pulse, the magnetization refocuses, generating an echo.

a)

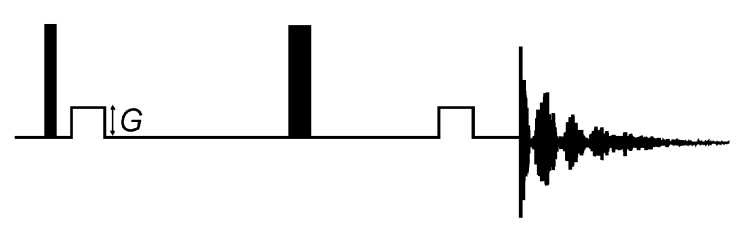

b)

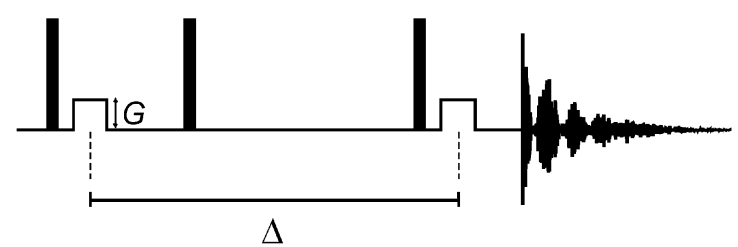

Fig. 1 Typical pulse sequences for the PGSE experiments: (a) the Stejskal-Tanner experiment; (b) the Stejskal-Tanner experiment, modified via substitution of two $90^{\circ}$ pulses for a single $180^{\circ}$ pulse.

*Paper based on a presentation at the $19^{\text {th }}$ International Conference on Physical Organic Chemistry (ICPOC-19), 13-18 July 2008, Santiago de Compostela, Spain. Other presentations are published in this issue, pp. 571-776. 
The first pulsed linear field gradient results in strong dephasing of the magnetization with a phase angle proportional to the length $(\delta)$ and the amplitude $(G)$ of the gradient. Because the strength of the gradient varies linearly along, e.g., the $z$-axis, only spins contained within a narrow slice of the sample acquire the same phase angle. The second gradient pulse reverses the respective phases, and the maximum echo signal, $I_{\mathrm{o}}$, forms in the usual way. Of course, the spins, which move out of their slice into neighboring areas via Brownian motion, that is, those which diffuse, will not be refocused by the second gradient and this leads to an attenuated echo signal, I. As smaller molecules or anions move faster, they translate during the time interval $\Delta$ into slices further apart from their origin, thus giving rise to smaller signal intensities. Repetition of the experiment with increasing gradient strengths, $G$, affords a set of points which lead to a straight line. The measured relative intensities, $I / I_{\mathrm{o}}$, can be used to extract the $D$ value in accordance with eq. 1

$$
\operatorname{Ln}\left(I / I_{\mathrm{o}}\right)=-\gamma^{2} \delta^{2} G^{2}(\Delta-\delta / 3) D
$$

where $\gamma_{X}=$ gyromagnetic ratio of the $X$ nucleus, $\delta=$ length of the gradient pulse, $G=$ gradient strength, $\Delta=$ delay between the midpoints of the gradients, and $D=$ diffusion coefficient. More elaborate pulse sequences have been proposed, and the stimulated spin-echo (see Fig. 1b) in which three $90^{\circ}$ pulses are used, has the advantage that the signals decay according to $T_{1}$ (spin-lattice relaxation time) rather than according to $T_{2}$ (spin-spin relaxation time). Since $T_{1}$ is normally longer than $T_{2}$, this sequence can provide a better signal-to-noise ratio. Measuring mixtures of rather different materials (thereby possibly recognizing the presence of higher-molecular-weight compounds) presents no problem as long as the appropriate resonances are well resolved.

A typical example [8] is given in Fig. 2 where the ${ }^{19} \mathrm{~F}$ signal from the smaller $\mathrm{BF}_{4}{ }^{-}$anion decreases faster than that from the slightly larger $\mathrm{CF}_{3} \mathrm{SO}_{3}{ }^{-}$anion and the slopes from both of these lines are larger than that for the tetraphenyl borate derivative, BArF.

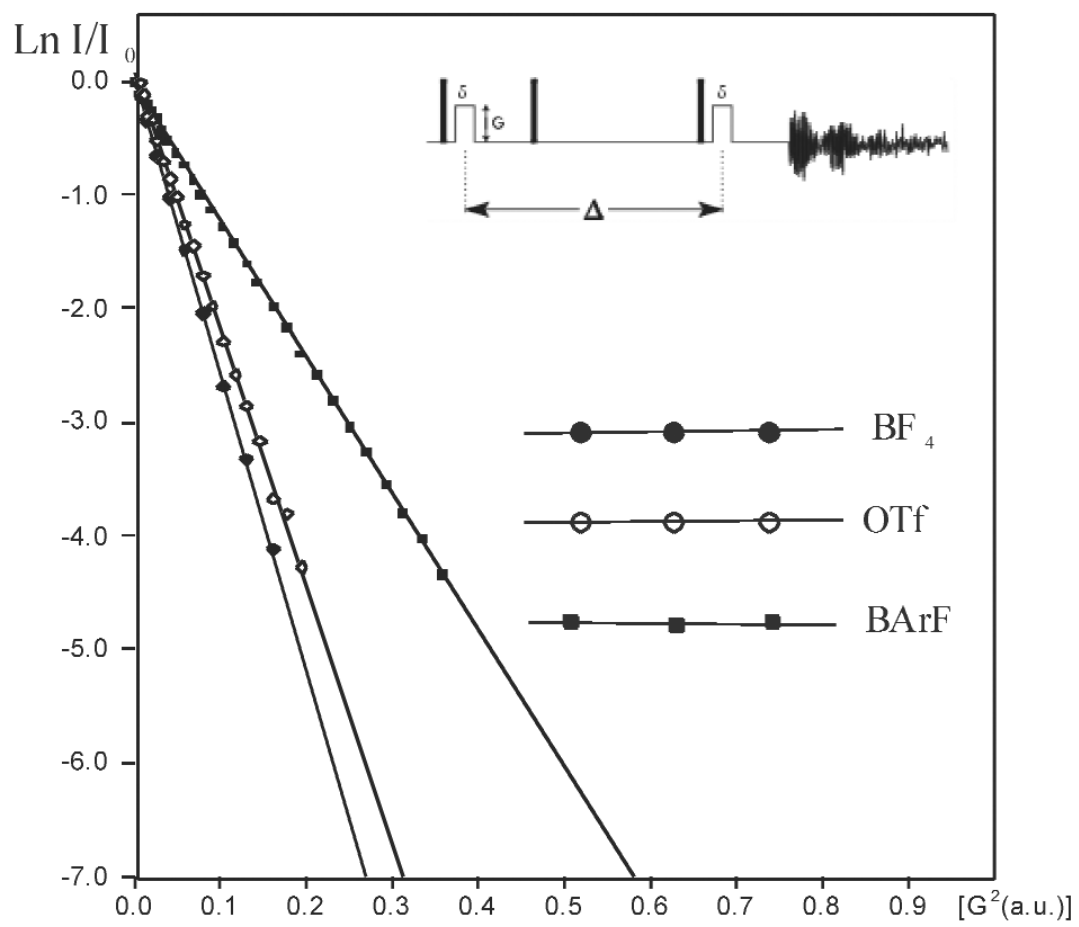

Fig. 2 The dependence of the slope of the line (and thus the $D$ values) on the size of the anion. 
The most common PGSE application involves determining the relative volume of a compound (or ion) via $r_{\mathrm{H}}$, the calculated hydrodynamic radius, from the Stokes-Einstein equation.

$$
r_{\mathrm{H}}=\frac{k T}{6 \pi \eta D}
$$

This equation has its drawbacks [9], and an empirical correction is often made; still it is widely used when comparing $D$ values involving data from differing solvents as it provides a correction for solvent viscosity, $\eta$.

\section{MOLECULAR VOLUMES AND HYDROGEN BONDING}

Without doubt, the most popular application of either the PGSE or (the two-dimensional variant, diffusion ordered spectroscopy, DOSY) methodologies concerns itself with the estimation of relative molecular volumes [10,11], and two review articles [1,2] summarize this type of application sufficiently. As the molecules become larger, they generally move slower with the result that the $D$ values are smaller and the radii, larger.

A common application in inorganic chemistry concerns the recognition of a monomer-dimer equilibrium and/or the assignment of a di- (or poly) nuclear rather than a mononuclear structure. We have recently [12] obtained ${ }^{1} \mathrm{H},{ }^{31} \mathrm{P}$, and ${ }^{7} \mathrm{Li}$ PGSE data for tetrahydrofuran (THF) and $\mathrm{Et}_{2} \mathrm{O}$ solutions of $\mathrm{LiPPh}_{2}$. Table 1 shows these PGSE results, and Scheme 1 gives the suggested structures. The larger $D$ value in $\mathrm{Et}_{2} \mathrm{O}$ relative to THF is due to the different viscosity. The $r_{\mathrm{H}}$ values indicate a much smaller volume of $\mathrm{LiPPh}_{2}$ in THF than in $\mathrm{Et}_{2} \mathrm{O}$. In $\mathrm{Et}_{2} \mathrm{O}$, all three nuclei $\left({ }^{7} \mathrm{Li},{ }^{1} \mathrm{H}\right.$, and $\left.{ }^{31} \mathrm{P}\right)$ afford the same $r_{\mathrm{H}}$ value, suggesting that they are translating at the same rate. In THF, the ${ }^{7} \mathrm{Li}$ diffusion constant is significantly smaller (and the $r_{\mathrm{H}}$ value larger) than those from the ${ }^{1} \mathrm{H}$ and ${ }^{31} \mathrm{P}$ measurements. One finds a septet in the ${ }^{31} \mathrm{P}$ NMR spectrum and a triplet in the ${ }^{7} \mathrm{Li}$ spectrum, both with ${ }^{1} \mathrm{~J}\left({ }^{7} \mathrm{Li},{ }^{31} \mathrm{P}\right)=44 \mathrm{~Hz}$ at $202 \mathrm{~K}$ in $\mathrm{Et}_{2} \mathrm{O}$, but no coupling is observed in THF, in agreement with the proposed structures. Consequently, we suggest that in THF, $\mathrm{LiPPh}_{2}$ exists as a mononuclear solvated species, whereas in $\mathrm{Et}_{2} \mathrm{O}$ a dinuclear structure dominates.

Table $1 D\left(\times 10^{10} \mathrm{~m}^{2} \mathrm{~s}^{-1}\right)$ and $r_{\mathrm{H}}(\AA)$ values ${ }^{\mathrm{a}}$ in THF and $\mathrm{Et}_{2} \mathrm{O}$ at room temperature.

\begin{tabular}{lccc}
\hline & Nucleus & $D^{\mathrm{b}}$ & $r_{\mathrm{H}}{ }^{\mathrm{c}}$ \\
\hline $\mathrm{LiPPh}_{2}(\mathrm{THF})$ & ${ }^{7} \mathrm{Li}$ & 10.1 & 4.7 \\
& ${ }^{1} \mathrm{H}$ & 11.0 & 4.3 \\
& ${ }^{31} \mathrm{P}$ & 11.0 & 4.3 \\
& & & \\
$\mathrm{LiPPh}_{2}\left(\mathrm{Et}_{2} \mathrm{O}\right)$ & ${ }^{7} \mathrm{Li}$ & 16.1 & 6.2 \\
& ${ }^{1} \mathrm{H}$ & 16.0 & 6.2 \\
& ${ }^{31} \mathrm{P}$ & 16.2 & 6.1 \\
\hline
\end{tabular}

\footnotetext{
aAll at $60 \mathrm{mM}$.

${ }^{b}$ Experimental error is ca. $\pm 2 \%$. Viscosity: (THF, 299

$\mathrm{K})=0.461 \cdot 10^{-3} \mathrm{Kg} \mathrm{s}^{-1} \mathrm{~m}^{-1},\left(\mathrm{Et}_{2} \mathrm{O}, 299 \mathrm{~K}\right)=$ $0.221 \cdot 10^{-3} \mathrm{Kg} \mathrm{s}^{-1} \mathrm{~m}^{-1}$.
} 


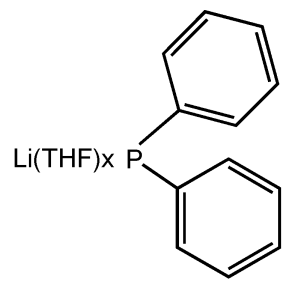<smiles>CCOP(c1ccccc1)c1ccccc1</smiles><smiles>C1COC(OC2CCCC2)(C2CCCC2)OC1</smiles><smiles>c1ccc(Pc2ccccc2)cc1</smiles><smiles>CCCCOC1([C@@H](c2ccccc2)P(c2ccccc2)c2ccccc2)OCCCO1</smiles><smiles></smiles>

Scheme 1 In THF solution, $\mathrm{LiPPh}_{2}$ exists primarily as separated ions (top left). Some complexation (lower left) cannot be completely excluded. $\mathrm{In}_{2} \mathrm{O}$, the dimeric structure (lower right) is thought to be correct.

The same approach is valid when discussing transition-metal complexes, as indicated in Scheme 2 [13]. The mononuclear $\mathrm{PtCl}_{2}(\mathrm{MeO}-\mathrm{Biphep})$ complex $(D=8.92)$ is considerably smaller than the dichloro-bridged dinuclear dicationic species that arises when a chloride is abstracted with $\mathrm{AgBF}_{4}$, $\left[D\right.$ cation $\left.=6.64 ; D\left(\mathrm{BF}_{4}^{-}\right)=10.51\right]$, and these differences in size are reflected in the measured $D$ values. 


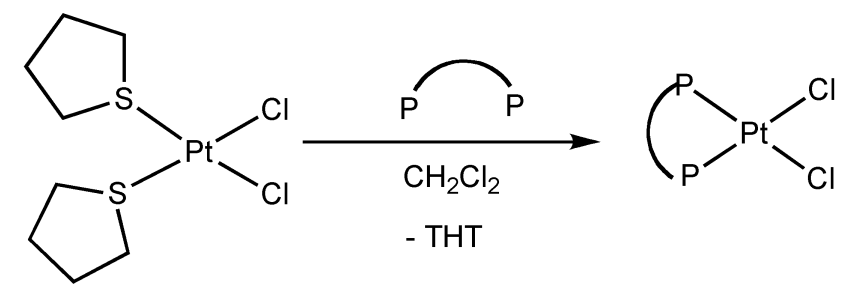<smiles>COc1cccc(P)c1-c1c(P)cccc1Pc1ccccc1</smiles>

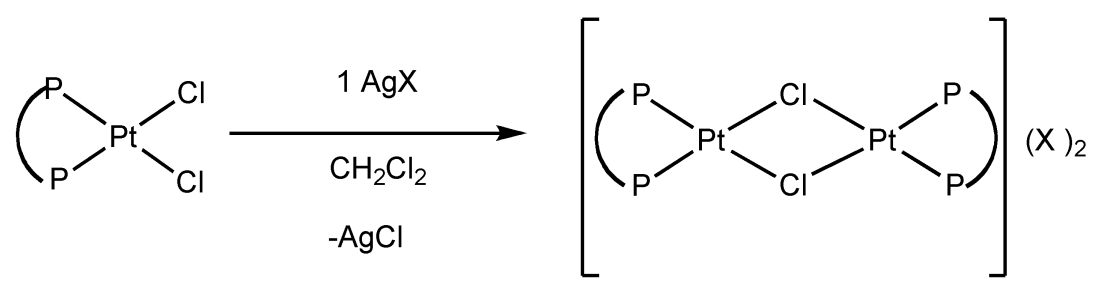

Scheme 2 Mono-and dinuclear MeO-Biphep Pt-complexes.

Diffusion data are also quite useful in connection with hydrogen bonding [14] in that a relatively small bound molecule or anion will diffuse considerably slower than the "free" species. In Scheme 3, the small $\mathrm{BF}_{4}^{-}$anion now translates at the same speed as the larger brucinium cation. In a similar fashion, when hydrogen bonded to a coordinated water molecule, the $\mathrm{BF}_{4}{ }^{-}$anion diffuses at the same rate as the relatively large chiral Ru cation.

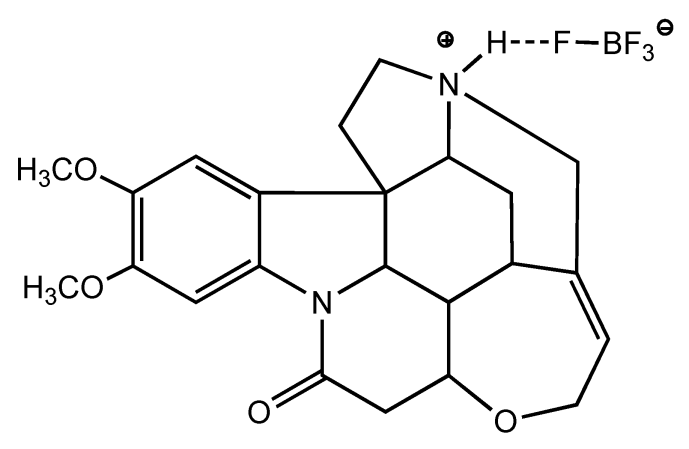

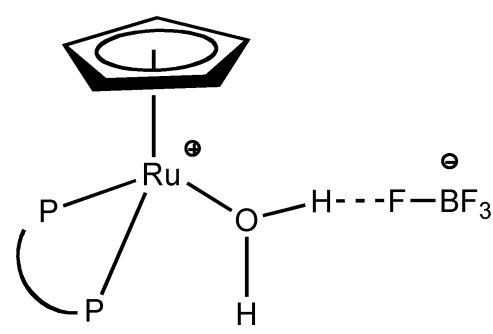

Brucinium salts $D$

$\mathrm{CD}_{2} \mathrm{Cl}_{2}$ cation 10.06

anion 9.98

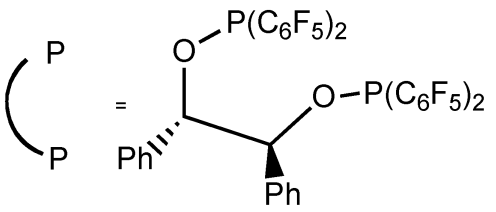

Scheme 3 Hydrogen bonding in a brucinium salt and a Ru-aquo-complex. 


\section{ION PAIRING}

The primary motivation for this article arises from the ability to use $D$ values to estimate the extent of ion pairing in a variety of salts. The subject of ion pairing is often discussed, but not frequently studied. This is partially because the available physical methods do not always provide enough detail and/or are not suitable for either the solvent or reaction conditions. Specifically, there is an ongoing discussion in the current literature concerned with "anion effects" on, e.g., relative kinetics in homogeneous catalysis [15]. The catalysts under discussion are frequently transition-metal salts, and the observed effects may or may not be related to ion pairing.

Relative to other physical methods, an analysis of the $D$ values is both rapid and instructive. If the diffusion characteristics of the anion and cation can be measured separately (easily done if the anion contains either a suitable ${ }^{19} \mathrm{~F}$ or ${ }^{1} \mathrm{H}$ nucleus) then inspection of the regression lines for the cation and anion is revealing. For cations and anions of very different size (and in the absence of, e.g., hydrogen bonding or encapsulation), the observation of identical $D$ values (Fig. 3, left plot), usually results from complete ion pairing. If the two values are different, the extent of the difference reflects the degree of ion pairing. Strongly solvated salts without much ion pairing (aqueous solutions or solutions in, e.g., DMF or methanol) will reveal two very different traces (right plot). For intermediate ion pairing-and this is often the case (see center plot) - the two lines have different but related slopes. For these salts, one usually measures the $D$ value of the cation via ${ }^{1} \mathrm{H} \mathrm{NMR}$ and that for the anion $\left(\mathrm{BF}_{4}^{-}, \mathrm{PF}_{6}^{-}\right.$, $\mathrm{CF}_{3} \mathrm{SO}_{3}^{-}, \mathrm{BArF}^{-}$, etc.) via ${ }^{19} \mathrm{~F} \mathrm{NMR}$, although for the tetraphenyl borate anions, $\mathrm{BPh}_{4}{ }^{-}$or $\mathrm{BArF}^{-}$, ${ }^{1} \mathrm{H}$ NMR is also quite suitable.

\section{Ion Pairs}

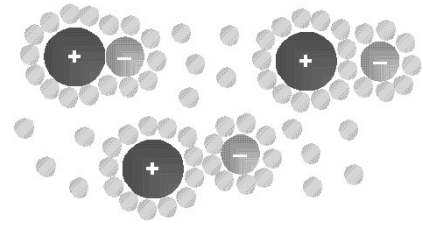

Strongly paired

$\mathrm{CHCl}_{3}$

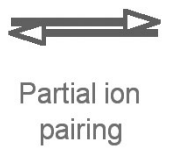

$\mathrm{CH}_{2} \mathrm{Cl}_{2}$
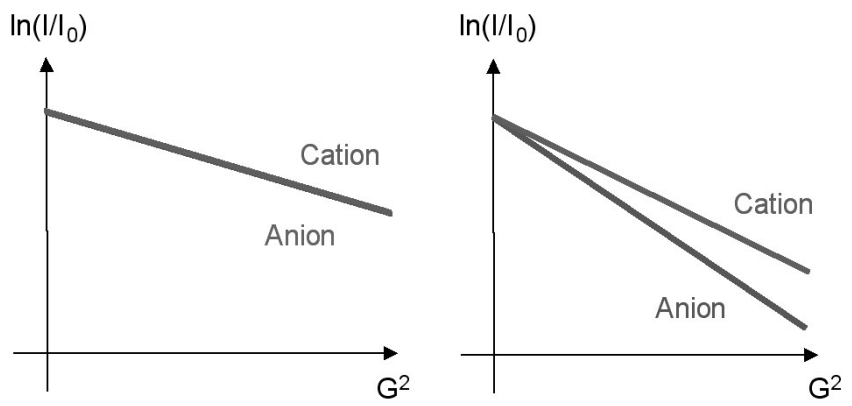

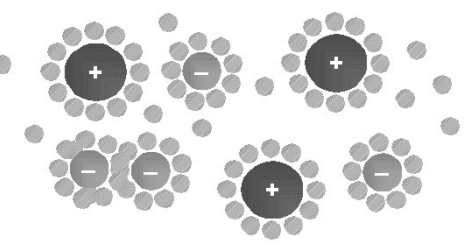

"Free lons

$\mathrm{MeOH}$

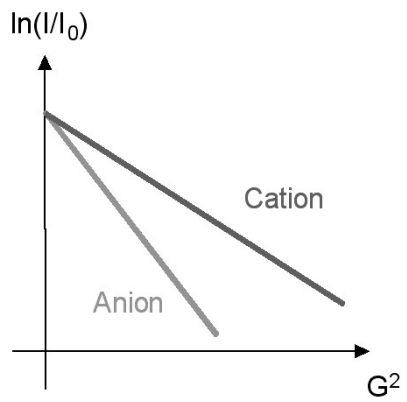

Fig. 3 Ion pairing and diffusion when the solvents have markedly different polarities.

The ease with which one can recognize differences in ion pairing, using this approach, is demonstrated by the data in Table 2 for the hydrogenation catalyst precursor $[\operatorname{Ir}(1,5-\mathrm{COD})(\mathrm{PHOX})]\left(\mathrm{BF}_{4}\right), \mathbf{1}$, as a function of solvent [16]. 
Table $2 D\left(\times 10^{10} \mathrm{~m}^{2} \mathrm{~s}^{-1}\right)$ and $r_{\mathrm{H}}(\AA)$ values for $[\operatorname{Ir}(1,5-\mathrm{COD})(\mathrm{PHOX})]\left(\mathrm{BF}_{4}\right)$ as a function of solvent [16].

\begin{tabular}{lcc}
\hline & $\mathrm{D}$ & $r_{\mathrm{H}}(\AA)$ \\
\hline & $\mathbf{C D C l}_{\mathbf{3}}$ & \\
Cation $\left({ }^{1} \mathrm{H}\right)$ & 7.23 & 5.7 \\
Anion $\left({ }^{19} \mathrm{~F}\right)$ & 7.43 & 5.6 \\
& $\mathbf{T H F}$ & \\
Cation $\left({ }^{1} \mathrm{H}\right)$ & 9.17 & 6.1 \\
Anion $\left({ }^{19} \mathrm{~F}\right)$ & 7.78 & 5.2 \\
& $\mathbf{C D}_{\mathbf{2}} \mathbf{C l}_{\mathbf{2}}$ & \\
Cation $\left({ }^{1} \mathrm{H}\right)$ & 9.72 & 5.5 \\
Anion $\left({ }^{19} \mathrm{~F}\right)$ & 13.79 & 3.9 \\
& $\mathbf{M e O H}$ & \\
Cation $\left({ }^{1} \mathrm{H}\right)$ & 7.58 & 5.5 \\
Anion $\left({ }^{19} \mathrm{~F}\right)$ & 16.62 & 2.5 \\
\hline aMeasured at $400 \mathrm{MHz}, 2 \mathrm{mM}, D$ values, $10^{-10} \mathrm{~m}^{2} \mathrm{~s}^{-1}$.
\end{tabular}<smiles>[R]c1ccccc1Pc1ccccc1C1=NC([R])CO1</smiles>

1, PHOX ligand, $\mathrm{R}_{1}=\mathrm{CH}_{3}$ and $\mathrm{R}_{2}=$ t-butyl

In a relatively nonpolar solvent such as $\mathrm{CDCl}_{3}$, the two $D$ (and $r_{\mathrm{H}}$ ) values are almost identical, indicating almost complete ion pairing. In methanol solution, the two $D$ values are very different, suggesting little or no ion pairing. THF and $\mathrm{CD}_{2} \mathrm{Cl}_{2}$ represent solvents in which one finds intermediate ion pairing. The uncorrected $r_{\mathrm{H}}$ value, $2.5 \AA$, for the $\mathrm{BF}_{4}^{-}$in methanol, provides an indication of the value to be expected for the solvated anion. Slightly larger values, ca. 2.8-2.9 $\AA$, are found for the $\mathrm{PF}_{6}{ }^{-}$anion. However, equally interesting is the solvent and temperature dependence of the ion pairing.

For the salt, $\mathrm{LiCPh}_{3}, \mathbf{2}$, synthesized as shown in eq. 3, there is strong ion pairing in THF solution at ambient temperature, based on ${ }^{7} \mathrm{Li}$, and ${ }^{1} \mathrm{H}$ diffusion

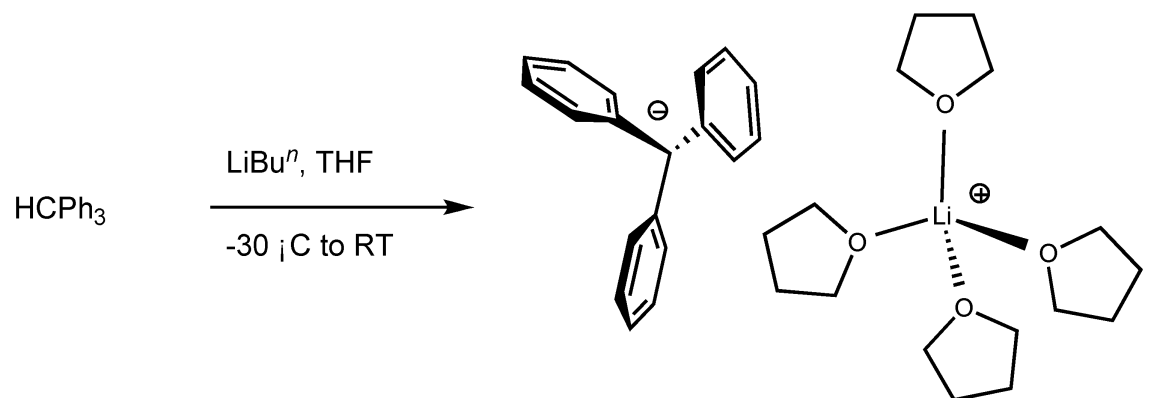


studies [17]. However, at $155 \mathrm{~K}$, based on the observed $D$ and $r_{\mathrm{H}}$ values, the separated ions are favored! The explanation lies in the known temperature dependence of the dielectric constant for a number of solvents. For THF, the solvent becomes about twice as polar at $155 \mathrm{~K}$ than at ambient temperature $(\varepsilon=$ 15.5, relative to 7.54 at $293 \mathrm{~K}$ ), with the result that the separated ions are favored at this lower temperature. The solid-state structure of $\mathbf{2}$ (crystallized from THF solution) affords metric data that are consistent with our solution studies and the reader is referred to the literature [4] for further NMR details, such as ${ }^{7} \mathrm{Li}$ line widths and chemical shifts, that support the discussion above. Before proceeding further, it is worth repeating that (1) this PGSE NMR approach readily allows recognition of strong (or weak) ion pairing; (2) $\mathrm{CDCl}_{3}$, the most commonly used solvent in solution studies of organic molecules, strongly favors ion pairing; and (3) low-temperature NMR studies will not only slow the rates of selected dynamics processes, but also influence the amount of ion pairing.

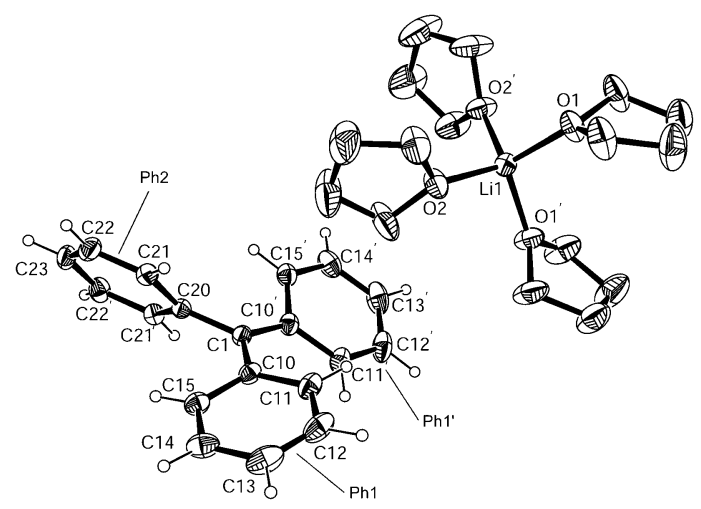

Fig. 4 Solid-state structure for $\mathrm{Li}(\mathrm{THF})_{4} \mathrm{CPh}_{3}, 2$, from THF solution [17].

To avoid using the $r_{\mathrm{H}}$ values from the Stokes-Einstein equation, we have suggested that the ratio $D$ (cation) $/ D$ (anion) can be a useful index [18], and this will be shown in many of the tables which appear later (in bold type). In connection with this ratio, we have recently advocated a three-pronged approach in an effort to better appreciate the various subtle factors involved in determining the extent of ion pairing. These three are: $D$ values, to recognize ion pairing, Overhauser data to provide some structural help with respect to where the anion prefers to position itself and a natural population analysis (NPA) based on density functional theory (DFT) calculations, to estimate the amount and placement of the positive charge.

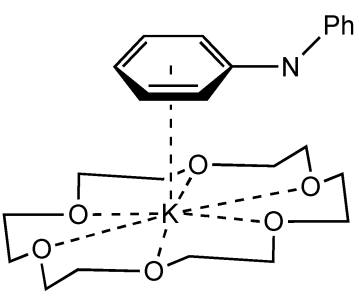

3

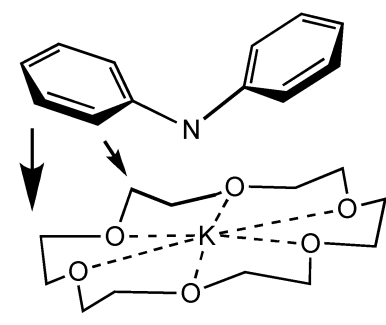

4

(solid-state structure) 
The value of the Overhauser measurements is nicely illustrated by an NMR study on the crown ether stabilized salt, $\left[\mathrm{K}\left(18\right.\right.$-crown-6) $\left.\left(\mathrm{NPh}_{2}\right)\right][16 \mathrm{~b}]$. The solid-state structure for this salt has been determined [19] and reveals a $\pi$-interaction between one of the aniline rings and the potassium atom, as indicated in 3. The measured diffusion data in THF solution for this salt are given in Table 3 along with $D$ values for $\mathrm{Ph}_{2} \mathrm{NH}$ and the free crown ether. Based on the diffusion data, the anilide anion and crown ether are moving at abut the same rate, i.e, there is a strong interaction between these two species leading to $r_{\mathrm{H}}$ values which are much larger than either of the two separate components.

Table $3 D\left(\times 10^{-10} \mathrm{~m}^{2} \mathrm{~s}^{-1}\right)$ and $r_{\mathrm{H}}(\AA)$ values ${ }^{\mathrm{a}}$ for $\left[\mathrm{K}\left(18\right.\right.$-crown-6) $\left.\left(\mathrm{NPh}_{2}\right)\right], \mathrm{X}, \mathrm{Ph}_{2} \mathrm{NH}$, and 18-crown-6, all in THF- $d_{8}$ at $299 \mathrm{~K}[16 \mathrm{~b}]$.

\begin{tabular}{llrrr}
\hline & \multicolumn{1}{c}{ Nucleus } & \multicolumn{1}{c}{$D^{\mathrm{b}}$} & $r_{\mathrm{H}}$ & $R^{\mathrm{c}}$ \\
\hline Sample 1 & ${ }^{1} \mathrm{H}\left(\mathrm{Ph}_{2} \mathrm{~N}^{-}\right)$ & 8.54 & 5.6 & \\
& ${ }^{1} \mathrm{H}\left(\mathrm{K}^{+}, 18\right.$-crown-6) & 8.44 & 5.6 & \\
$\mathrm{Ph}_{2} \mathrm{NH}$ & ${ }^{1} \mathrm{H}$ & 13.82 & 3.5 & 3.6 \\
18 -crown-6 & ${ }^{1} \mathrm{H}$ & 12.69 & 3.7 & 4.3 \\
\hline
\end{tabular}

\footnotetext{
a $43 \mathrm{mM}$.

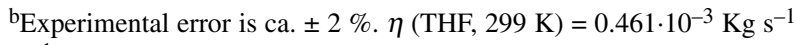
$\mathrm{m}^{-1}$.

${ }^{\mathrm{c}}$ Estimated by using Chem3D averaging the distances between the centroid and the outer hydrogen.
}

However, the ${ }^{1} \mathrm{H}$ spectrum for $\left[\mathrm{K}\left(18\right.\right.$-crown-6) $\left.\left(\mathrm{NPh}_{2}\right)\right]$ shows that the two $\mathrm{N}$-phenyl groups are equivalent on the NMR time scale. Moreover, the ${ }^{1} \mathrm{H},{ }^{1} \mathrm{H}$ NOESY spectrum of this salt (Fig. 5) reveals strong selective contacts from the crown ether $\mathrm{CH}_{2}$ protons to the ortho and meta phenyl protons, with the former stronger than the latter. There are no contacts to the para protons, so that this position must be remote from the crown ether, i.e., structure $\mathbf{3}$ is not correct in solution. Consequently, based on the nuclear Overhauser effect (NOE) results in THF solution, we favor an ion-paired structure, 4, in which the $\mathrm{NPh}_{2}$ anion approaches the complexed potassium cation via the $\mathrm{N}$-atom, thus bringing the ortho and meta — but not the para — phenyl protons proximate to the crown ether ring.

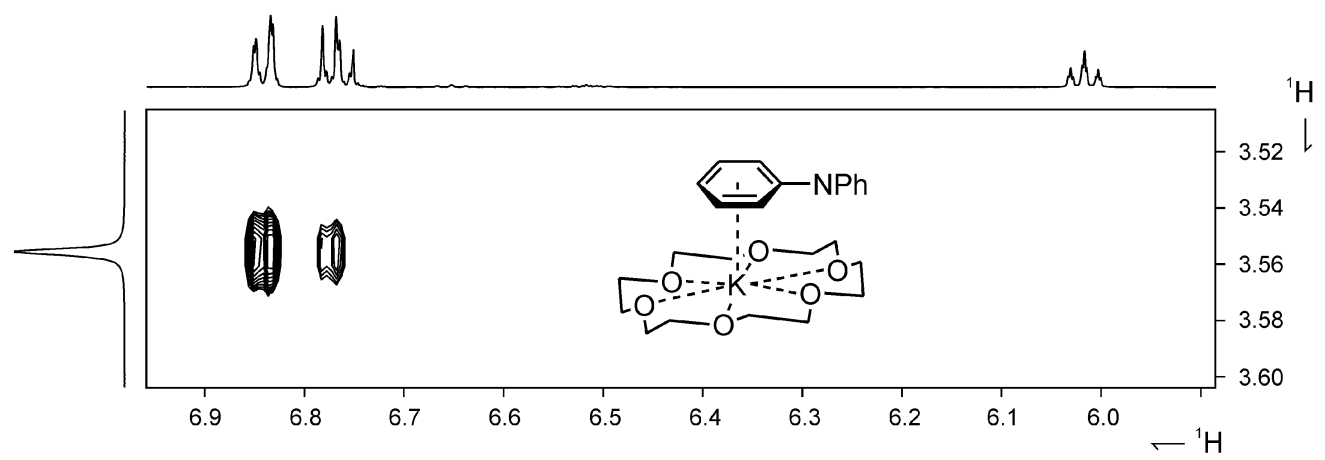

Fig. 5 The ${ }^{1} \mathrm{H},{ }^{1} \mathrm{H}$ NOESY spectrum of $\left[\mathrm{K}\left(18\right.\right.$-crown-6) $\left.\left(\mathrm{NPh}_{2}\right)\right]$ reveals selective contacts from the crown ether $\mathrm{CH}_{2}$ protons to the ortho and meta phenyl protons. There are no contacts to the para protons. Note that the two phenyl rings are equivalent $[16 \mathrm{~b}]$. 
Macchioni and coworkers $[9,20]$ in a series of papers have made specific use of ${ }^{19} \mathrm{~F},{ }^{1} \mathrm{H}$ HOESY (heteronuclear Overhauser spectroscopy) measurements on transition-metal salts, and have shown that this is a viable method for placing the fluorine-containing anions relative to their cations, in three-dimensional space. However, this approach is quite general. The ${ }^{1} \mathrm{H},{ }^{19} \mathrm{~F}$ HOESY spectra of $\mathrm{NBu}_{4}\left(\mathrm{BF}_{4}\right)$, 5, left, and $\mathrm{MePPh}_{3}\left(\mathrm{PF}_{6}\right), \mathbf{6}$, right, are given in Fig. 6. For the ammonium salt, it is clear that the F-atoms of the anion "see" all of the aliphatic protons, almost equally. However, for the phosphonium salt one observes positional selectivity. The anion comes close to the methyl and ortho ring protons, but remains remote from the meta and para protons. One can understand this in terms of the anion approaching the positive P-atom of $\mathbf{6}$ from the sterically most accessible side of the cation.
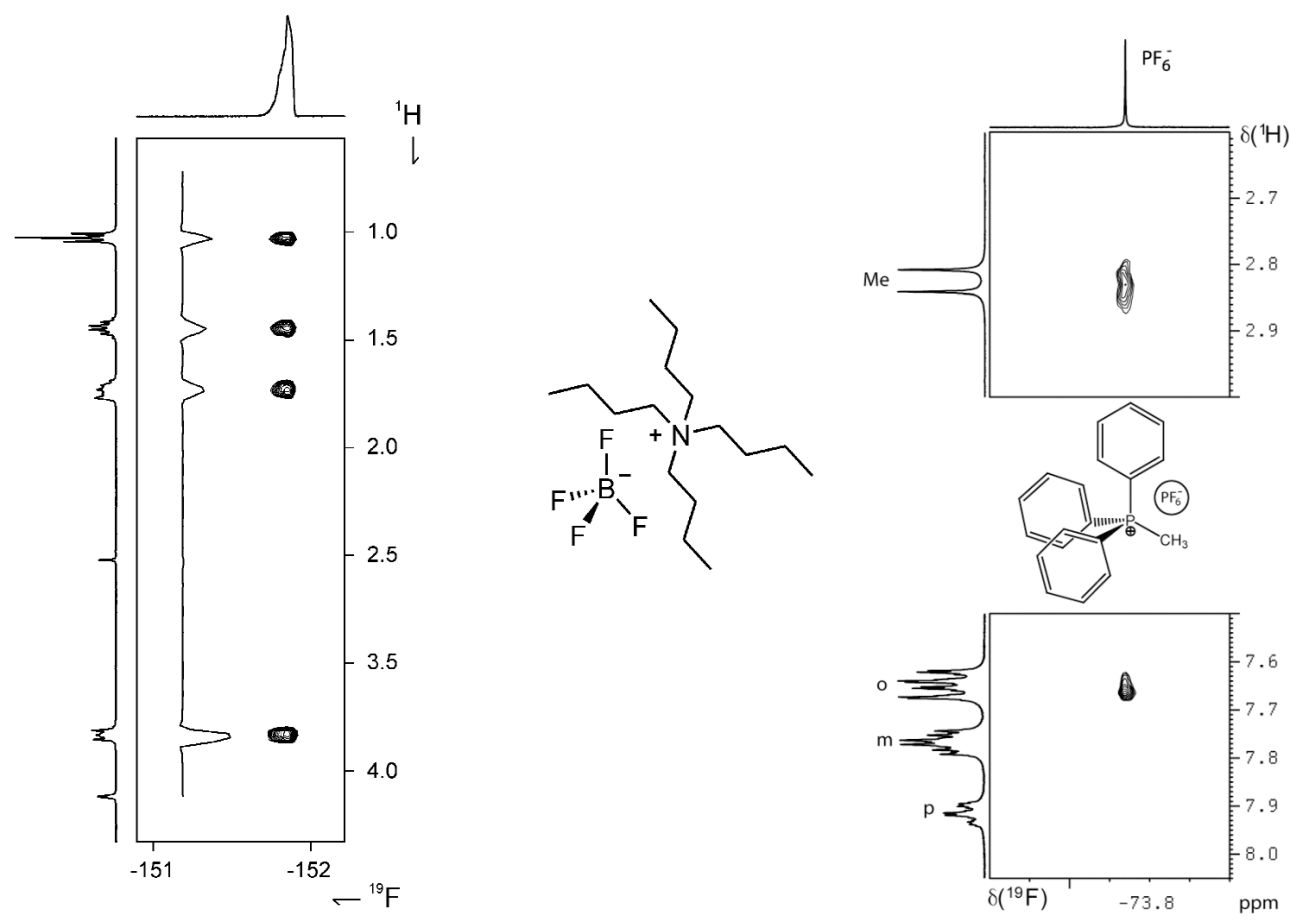

Fig. $6{ }^{1} \mathrm{H},{ }^{19} \mathrm{~F}$ HOESY spectra of 2 mmol solutions of $\mathrm{NBu}_{4}\left(\mathrm{BF}_{4}\right), \mathbf{5}$, (left, THF) and $\mathrm{MePPh}_{3}\left(\mathrm{PF}_{6}\right), 6$ (right, $\mathrm{CD}_{2} \mathrm{Cl}_{2}$ ).

This type of cation/anion structural selectivity is quite common [1,2,20a]. For example, in the organic heterocyclic salts 7 and $\mathbf{8}$, see Scheme 4 , one finds selective ${ }^{1} \mathrm{H},{ }^{19} \mathrm{~F}$ HOESY contacts (indicated by the arrows), so that the $\mathrm{PF}_{6}{ }^{-}$anion approaches the positive $\mathrm{N}$-atom preferentially from one side. In 6-8, and many other salts, the relative position of the anion in solution strongly depends on steric effects; however, there are some important exceptions. 


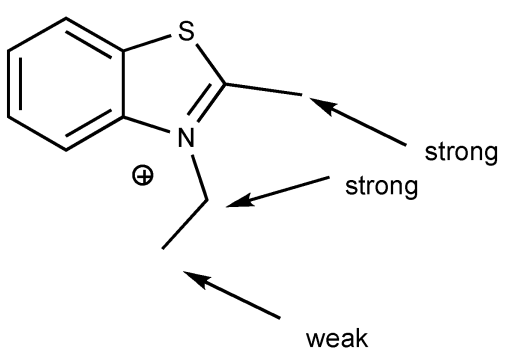

7

$\begin{array}{llc}\text { Cmpd } & \text { fragment } & D \\ \mathbf{7} & \text { cation } & 14.12 \\ & \text { anion } & 14.57 \\ & & \\ \mathbf{8} & \text { cation } & 11.17 \\ & \text { anion } & 12.14\end{array}$

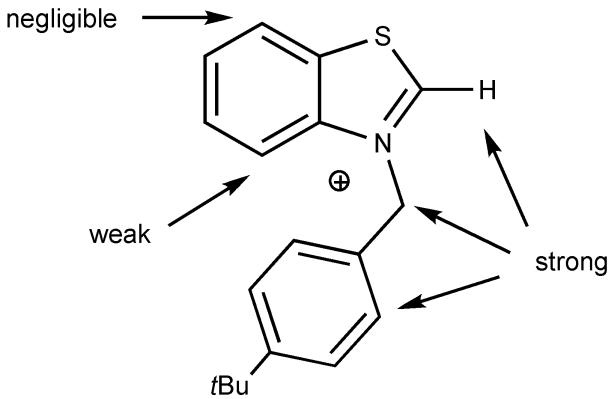

8

Scheme 4 Position of the $\mathrm{PF}_{6}{ }^{-}$anion and diffusion data in $\mathrm{CD}_{2} \mathrm{Cl}_{2}$ [18].

The salts 9 and 10 [18] (the $\mathrm{PF}_{6}{ }^{-}$analog of the $\mathrm{BF}_{4}{ }^{-}$salt in Fig. 6) both contain $n$-butyl groups attached to a positive center. However, in 9 there is partial negative charge on the chloride donor so that the anion prefers to avoid approaching the metal and P-atoms via the relatively "open" chloride route. This has consequences as indicated in Fig. 7. The ${ }^{1} \mathrm{H},{ }^{19} \mathrm{~F}$ HOESY cross-peaks for the $\mathrm{PCH}_{2}$ and $\mathrm{PCH}_{2} \mathrm{CH}_{2}$ resonances in $\mathbf{9}$ are much weaker than those for the $\mathrm{NCH}_{2}$ and $\mathrm{NCH}_{2} \mathrm{CH}_{2}$ analogs in $\mathbf{1 0}$. The anion finds it more difficult to push past the six $n$-butyl chains and spends most of the time close to the $\mathrm{PCH}_{2} \mathrm{CH}_{2} \mathrm{CH}_{2} \mathrm{CH}_{3}$ protons. This tendency for the anion to avoid formally negatively charged donors in metal complexes has been recognized earlier [20] and will be shown to be fairly general.

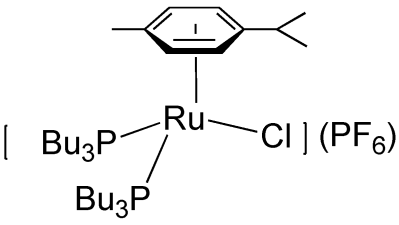

9<smiles>CCCCC(C)(C)N</smiles>

$\left(\mathrm{PF}_{6}\right)$ 

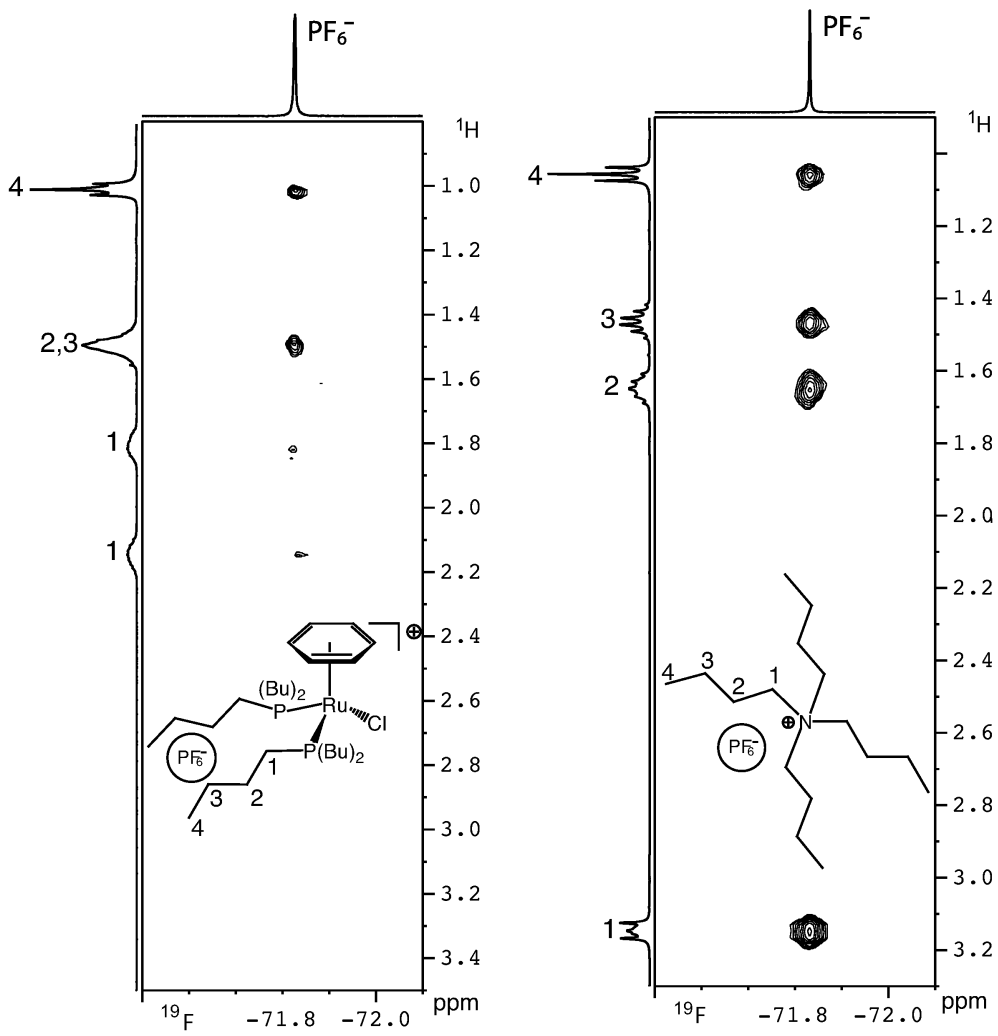

Fig. $7{ }^{1} \mathrm{H},{ }^{19} \mathrm{~F}$ HOESY spectra for $2 \mathrm{mmol}$ solutions of $\mathbf{9}$ and $\mathbf{1 0}$ in $\mathrm{CD}_{2} \mathrm{Cl}_{2}$ [18].

An NPA shows, as expected, that there is a significant amount of positive charge on the N-and $\mathrm{P}$-atoms of the various salts. Interestingly, the calculations do not always show a great deal of positive charge on the transition metal and the complexes 11 (Scheme 5) are representative [18]. The scheme shows the measured $D$ values for these $\mathrm{Cp}^{*}$ complexes, the solid-state structure for the fluoro-benzene salt, and the calculated charges for the $\mathrm{Cp}$ analogs of 11. In all cases, there is a significant amount of ion pairing for these salts in $\mathrm{CD}_{2} \mathrm{Cl}_{2}$ solution. From the solid-state structure in the scheme it is clear that the anion approaches both the $\mathrm{Cp}^{*}$ and the coordinated arene and that the observed closest contacts are under $3 \AA$ for both rings. These relatively short contacts are consistent with the postulated strong ion pairing from the diffusion data. Although the Ru-atom is formally in the oxidation state $2+$, it does not carry most of the positive charge. Both the $\eta^{6}$-arene and the $\eta^{5}$-Cp are more positive than this metal center. Presumably, the metal acts as something of a buffer and helps to distribute the positive charges via both the $\sigma$ - and $\pi$-bonding pathways.

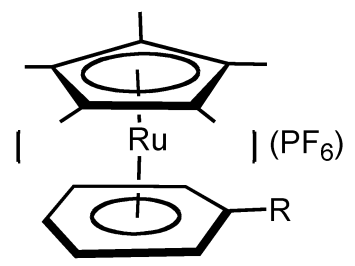




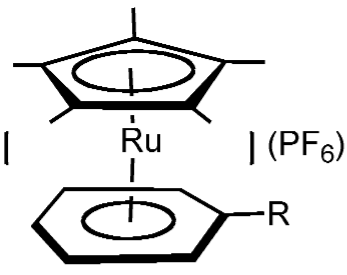

$\begin{array}{lll}\text { 11a } R=H, & \text { 11b } & R=M e O \\ \text { 11c } R=F, & \text { 11d } & R=\mathrm{SiMe}_{3}, \\ \text { 11e } R=\mathrm{CO}_{2} \mathrm{Me}, 11 f & R=\mathrm{NO}_{2}\end{array}$

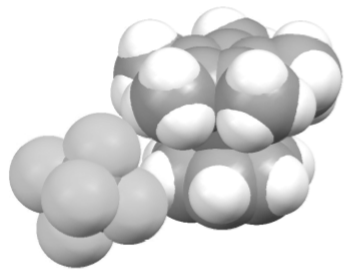

D D(cation/anion)

11a cation 12.510 .944 .34 .9

anion $13.30 \quad 4.04 .7$

11b cation 12.420 .954 .34 .9

anion $13.02 \quad 4.14 .7$

11c cation 12.390 .964 .34 .9

anion $12.95 \quad 4.14 .7$

11d cation 11.670 .924 .55 .2

anion $12.65 \quad 4.24 .8$

11e cation 12.100 .924 .45 .0

anion $13.14 \quad 4.04 .7$

11 cation 11.750 .964 .55 .1

anion $12.28 \quad 4.35 .0$

Partial positive Charges from the NPA analysis of the Cp analogs of $\mathbf{1 1 .}$

$\begin{array}{lllr} & \mathrm{Ru} & \mathrm{Cp} & \text { Arene } \\ \text { 11a } \mathrm{R}=\mathrm{H} & 0.21 & 0.32 & 0.47 \\ \text { 11b } \mathrm{R}=\mathrm{MeO} & 0.20 & 0.29 & 0.51 \\ \text { 11c } \mathrm{R}=\mathrm{F} & 0.19 & 0.34 & 0.47 \\ \text { 11f } \mathrm{R}=\mathrm{NO}_{2} & 0.21 & 0.38 & 0.41\end{array}$

Scheme $5 D$ values and charge distribution for 11. The $r_{\mathrm{H}}$ values, uncorrected and corrected [18] are shown to the right of the cation/anion ratio $\left(2 \mathrm{mmol}, \mathrm{CD}_{2} \mathrm{Cl}_{2}\right)$.

\section{THREE-PRONGED APPROACH}

Table 4 shows diffusion data for a series of metal complexes in $\mathrm{CD}_{2} \mathrm{Cl}_{2}$ solution, and it is convenient to analyze these data using our three-pronged approach. We will assume that the $D$ (cation) $/ D$ (anion) ratio qualitatively reflects differences in the amount of ion pairing and that values of this ratio approaching 1 imply relatively strong ion pairing. 
Table $4 D\left(\times 10^{-10} \mathrm{~m}^{2} \mathrm{sec}^{-1}\right)$ and $r_{\mathrm{H}}(\AA)$, values in $\mathrm{CD}_{2} \mathrm{Cl}_{2}$ for $\mathrm{PF}_{6}^{-}$salts [18].

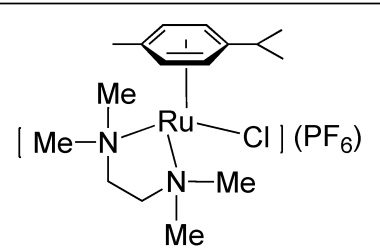

12
$\mathrm{r}_{\mathrm{H}}$

4.9

4.7

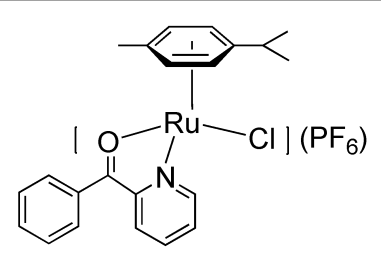

13 cation

$\mathrm{PF}_{6}$ 10.9

11.7
$D(2.7 \mathrm{mM}, \mathbf{0 . 9 3})$

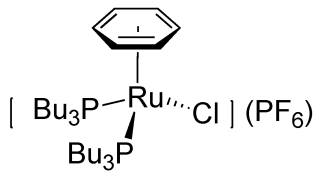

$$
D(2 \mathrm{mM}, \mathbf{0 . 8 6})
$$

cation

$\mathrm{PF}_{6}^{-}$ 8.49 9.87

\section{$\mathrm{r}_{\mathrm{H}}$}

6.6

5.8

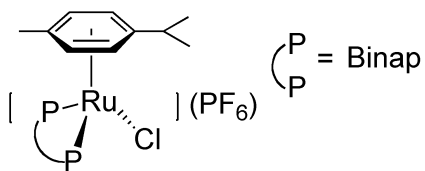

14 $D(2 \mathrm{mM}, \mathbf{0 . 7 2}) \mathrm{r}_{\mathrm{H}}$ 7.87

10.99

5.5
$11.6 \quad 4.5$

12.5

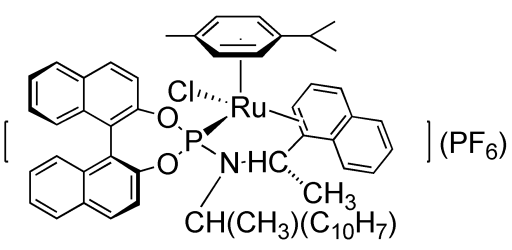

15

$\begin{array}{lll} & D(2.0 \mathrm{mM}, \mathbf{0 . 6 9}) & \mathrm{r}_{\mathrm{H}} \\ \text { cation } & 8.18 & 7.0 \\ \mathrm{PF}_{6}^{-} & 11.8 & 5.2\end{array}$

(continues on next page) 
Table 4 (Continued).

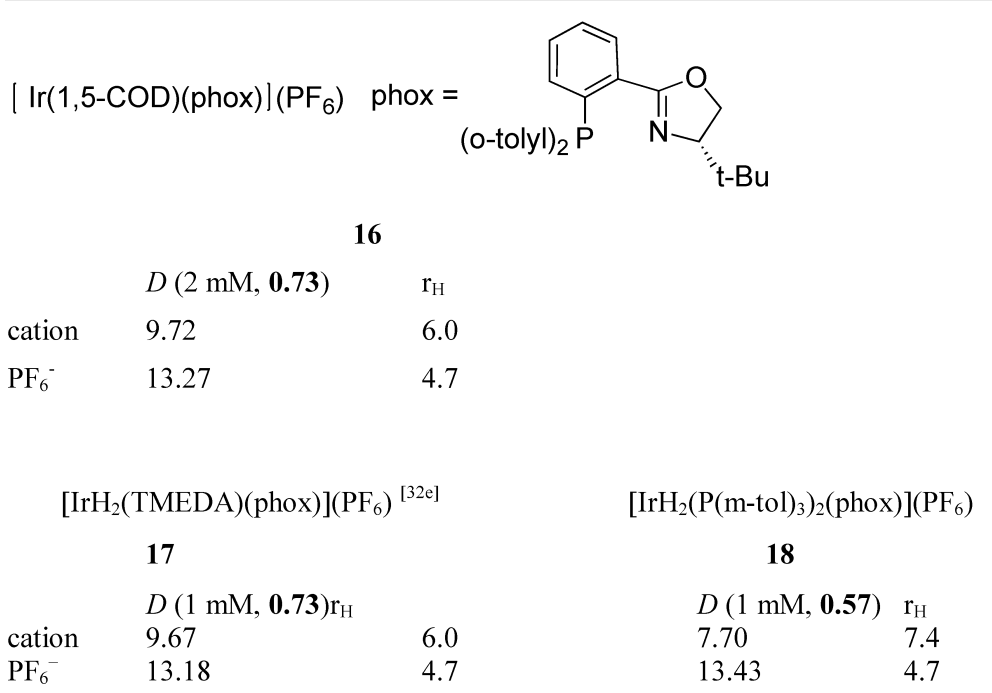

Starting with the set of Ru salts, the largest $D$ (cation) $/ D$ (anion) ratio in Table $4,0.93$, is found for the [RuCl(TMEDA)( $\eta 6$-cymene)], 12, [9a], and benzoyl pyridine cations, 13 [31d]. This Ru-TMEDA salt with its two partially positively charged ammonium like $\mathrm{N}$-atoms concentrates the positive charge near the metal. Combined with the relatively small size of this five-membered ring chelating ligand, the anion has no problem in approaching, as shown by Overhauser studies. The bis $\mathrm{P}\left(\mathrm{Bu}_{3}\right)$ phosphine 9 [47], [ $D($ cation $) / D($ anion) ratio $=0.86]$, with its longer chains and modestly bulky ligands will keep the anion a little further away from the positive P-atoms as noted above in the discussion of the HOESY spectrum for 9. For the BINAP salt 14 [49], with almost the same donor set as in 9, the smaller $D$ (cation) $/ D$ (anion) ratio, 0.72 , arises because the anion has to find its way past the bulky BINAP BINAPhthyl moiety in order to approach the positive P-atoms. Salt 15 [29], with its even larger phosphoramidite ligand, has the same problem.

The smallest $D$ (cation) $/ D$ (anion) ratio, 0.57 , in the iridium series, stems from the $\operatorname{Ir}(\mathrm{III})$ hydride, $\left[\operatorname{IrH}_{2}\left\{\mathrm{P}(\mathrm{m}-\mathrm{tol})_{3}\right\}_{2}(\right.$ phox $\left.)\right]$, cation, 18 [46]. This Ir tris-phosphine oxazoline salt [32e] reveals the smallest ratio (the least ion pairing) because (a) the positive charges are likely to be distributed across a number of centers (three P-atoms and one $\mathrm{N}$-atom in addition to the adjacent carbon atoms) and (b) the approach of the anion is hindered by the three bulky tertiary phosphine donors which, together possess nine substituted aromatic moieties. One finds no HOESY contacts to the hydride ligands as these are partially negatively charged, thereby forcing the anion to take a more hindered approach. Salt 17, with the smaller chelating TMEDA ligand and salt 16, with the modest size 1,5-cyclo-octadiene (COD) chelate, give larger, but still rather modest $0.73 D$ (cation) $/ D$ (anion) ratios. Interestingly, the 1,5-COD ligand is not very positive, perhaps due to $\pi$-back-bonding.

The organic salts $\mathbf{1 9}$ and $\mathbf{2 0}$ are pertinent in that they both show very modest $D$ (cation) $/ D$ (anion) ratios. The cyanine salt, $\mathbf{1 9}$, has the positive charge distributed over two remote $\mathrm{N}-\mathrm{C}=\mathrm{CH}$ fragments, and this is also supported by the NPA results [18]. This delocalization weakens the ion pairing (the HOESY spectrum [18] shows that the anion sits almost exactly between the two $\mathrm{N}$-atoms such that the two equivalent vinyl protons show the strongest contacts). Once again, there is a specific structure since the single $=\mathrm{CH}$ vinyl proton does not show any NOE contacts to the anion. For carbo-cation 20, the charges found from the NPA calculations suggest that the carbonium ion carbon, is only modestly positive (+0.12), whereas C9 and C42 (directly attached to the electronegative O-atoms) carry most of the charge (+0.40). Perhaps the observed reduced amount of ion pairing is due to the charge separation and 


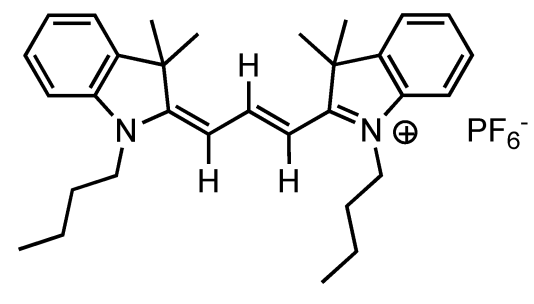

$19(\mathrm{D}=68)$

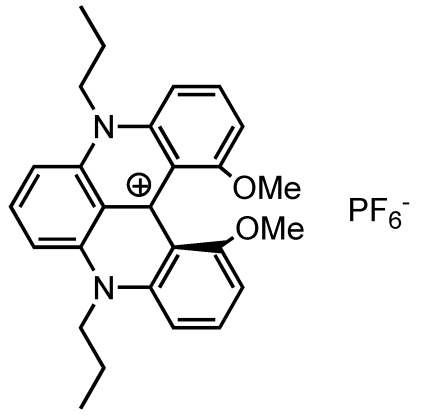

$20(\mathrm{D}=66)$

the reluctance of the anion to approach the O-atoms. Unfortunately, we have not been able to obtain HOESY data for 20, despite several attempts.

\section{CO-OLEFIN POLYMERIZATION}

In the copolymerization of styrene with $\mathrm{CO}$ using as catalyst precursor the $\mathrm{Pd}$ oxazoline salt, $[\mathrm{Pd}\{(\mathrm{R}, \mathrm{S})$ Bz-BIOX $\left.\}\left(\mathrm{CH}_{3}\right)\left(\mathrm{NCCH}_{3}\right)\right]$ (anion), 21, one finds an anion dependence of the observed weight of copolymer (cp) per gram of Pd [21]. Specifically, the values are 59, 85, and $109 \mathrm{~g} \mathrm{cp} / \mathrm{g} \mathrm{Pd}$ for the $\mathrm{CF}_{3} \mathrm{SO}_{3}{ }^{-}, \mathrm{BF}_{4}^{-}$, and $\mathrm{PF}_{6}{ }^{-}$salts, respectively. Although a significant degree of ion pairing was found in all three salts, based on the PGSE diffusion data in each complex (not shown [21]), the variation in the $r_{\mathrm{H}}$ values for the anions within the three anions was modest and appeared to be fairly typical for dichloromethane solutions, i.e., intermediate ion pairing. Interestingly, the ${ }^{1} \mathrm{H},{ }^{19} \mathrm{~F}$ HOESY spectra for these three salts, show that the $\mathrm{BF}_{4}{ }^{-}$and $\mathrm{PF}_{6}{ }^{-}$anions take up selective positions, on the side of the $\mathrm{Pd}$ complex remote from the oxazoline benzyl groups, relatively close to the acetonitrile ligand, but away from the formally negatively charged methyl anion [21]. The observed NOE selectivity involves interactions with one set of benzyl and oxazoline protons, those close to the acetonitrile, but not the other set. On the other hand, in the $\mathrm{CF}_{3} \mathrm{SO}_{3}{ }^{-}$salt, the anion does show a contact to the methyl ligand (as well as the other selective contacts) and therefore can be near to or occupying a pseudo fifth coordination position on the side of the cation remote from the two benzyl groups. Possibly the larger size of the $\mathrm{CF}_{3} \mathrm{SO}_{3}{ }^{-}$and/or its stronger tendency to coordinate, places this anion in a slightly disadvantageous position with respect to the necessary olefin complexation which will, eventually, lead to the copolymer. In any case, this position for the $\mathrm{CF}_{3} \mathrm{SO}_{3}{ }^{-}$anion results in a somewhat less efficient catalyst.

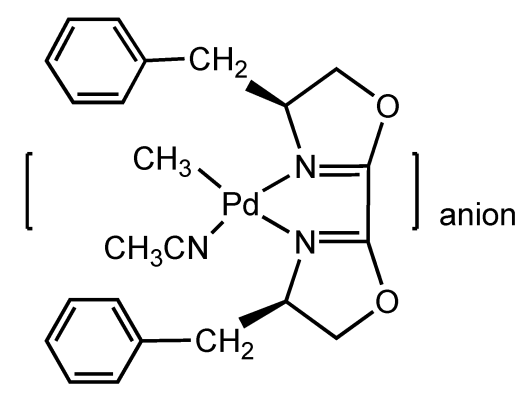

21 


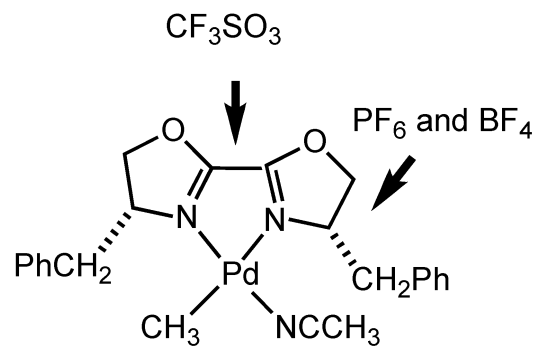

\section{DIELS-ALDER CHEMISTRY}

For the Ru-catalyzed enantioselective Diels-Alder condensation shown in Scheme 6 [22a,b], one finds that the proper choice of the anion results in a significantly faster (but not more enantioselective) process. The observed rates decreased in the order $\mathrm{BArF}^{-}>\mathrm{SbF}_{6}{ }^{-}>\mathrm{PF}_{6}{ }^{-}>\mathrm{BF}_{4}{ }^{-}$. The results from the detailed PGSE and Overhauser NMR studies [23] can be summarized in the following fashion:
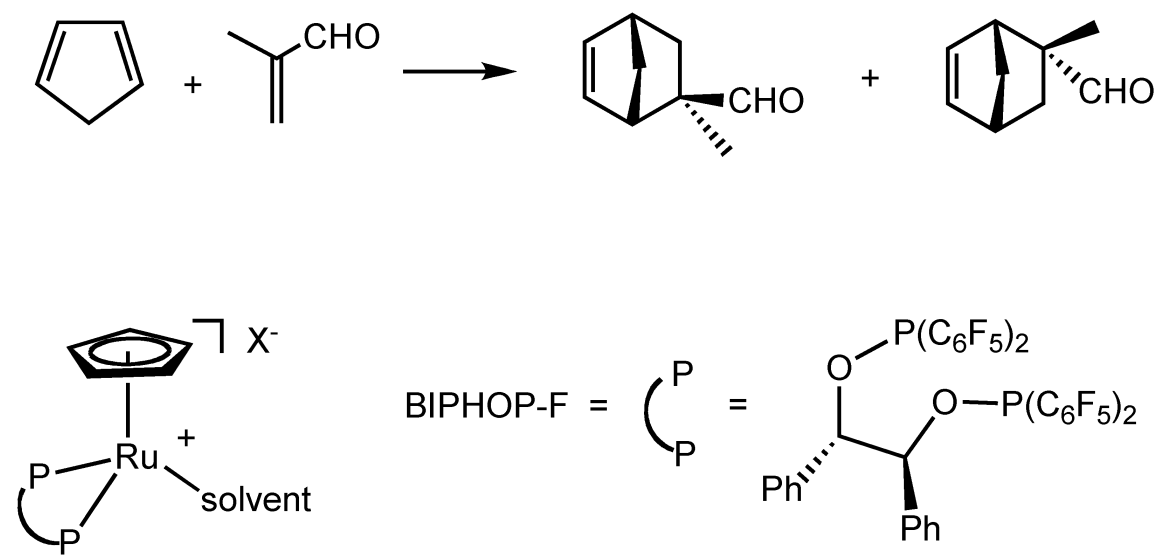

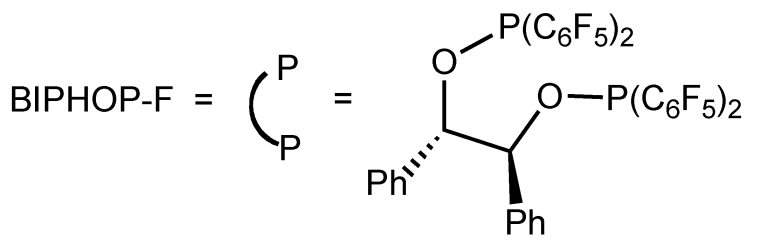

Scheme 6 Diels-Alder condensation and the $\eta^{5}-\mathrm{C}_{5} \mathrm{H}_{5}$ Ru-catalyst [22a,b].

1. Diffusion studies on a series of model complexes and especially the data from the two acrylonitrile model catalyst precursors, $\left[\mathrm{Ru}\left(\eta^{5}-\mathrm{C}_{5} \mathrm{H}_{5}\right)\left(\mathrm{CH}_{2}=\mathrm{CHCN}\right)(\mathrm{BIPHOP}-\mathrm{F})\right][\mathrm{Y}]$, and $\left[\mathrm{Ru}\left(\eta^{5}-\mathrm{C}_{9} \mathrm{H}_{7}\right)\left(\mathrm{CH}_{2}=\mathrm{CHCN}\right)(\mathrm{BIPHOP}-\mathrm{F})\right][\mathrm{Y}]$, with various Y-anions [23], in $\mathrm{CD}_{2} \mathrm{Cl}_{2}$ solutions afforded relatively large $r_{\mathrm{H}}$ values for the $\mathrm{BF}_{4}{ }^{-}$anions, suggesting more than expected ion pairing.

2. For $\mathrm{Y}=\mathrm{BArF}$, in $\mathrm{CD}_{2} \mathrm{Cl}_{2}$ solution, the two model catalysts result in $r_{\mathrm{H}}$ values for the $\mathrm{BArF}$ salts, which would be considered as arising from very weak ion pairing.

3. The ${ }^{1} \mathrm{H}_{-}{ }^{19} \mathrm{~F}$ HOESY spectra for these salts reveal selective contacts to the vinyl protons of the acrylonitrile, the $\eta^{5}$-ligand, and additional contacts to the ortho protons of one of the phenyl groups, whereas there are no HOESY contacts from the BArF to the cation.

If the $\mathrm{BF}_{4}{ }^{-}$anion ion-pairs relatively strongly, it might well interfere with the complexation of the dienophile oxygen donor of the aldehyde or decrease the rate of aldehyde (product) exchange once the condensation has occurred. Either of the above would be sufficient to slow the reaction. The BArF ${ }^{-}$ anion is not so strongly ion-paired and the HOESY (and X-ray data, not discussed here) reveal little or 
no contacts to the cation. The increased distance of this anion from the reactive site would provide a rational for the higher turn-over frequency of the catalyst.

\section{CONCLUSIONS}

Diffusion data from PGSE NMR measurements provide a qualitative estimation of the amount of ion pairing when both the cation and anion resonances can be studied separately. Given a sufficient empirical database, the $D$ (cation $/ D$ (anion) ratio, which does not rely on the Stokes-Einstein relation, may help in providing a qualitative feeling as to the extent of the ion pairing. Both ${ }^{1} \mathrm{H},{ }^{1} \mathrm{H}$ and ${ }^{1} \mathrm{H},{ }^{19} \mathrm{~F}$ Overhauser studies help to place the anion relative to the cation and clearly demonstrate that anions do not move arbitrarily around the periphery of the cation. An estimation of the charge distribution (via NPA or other methods), together with the NOE and PGSE results, provides a reasonable picture of how cations and anions interact in solution. Whether one is dealing with inorganic or organic salts, the positive charge distribution, together with the ability of the anion to approach the positively charged positions (steric effects due to molecular shape), represent the determining factors in the extent of ion pairing. For the case of transition-metal complexes, despite the relatively small size of, e.g., a hydride or even a chloride ligand, the anion will not approach formally negatively charged donors $[14,15]$. This combined approach will help to rationalize observed experimental anion effects, in, for example, homogeneous catalysis.

\section{ACKNOWLEDGMENTS}

P.S.P. thanks the Swiss National Science Foundation, the ETH Zurich and COST D40 for support, as well as the Johnson Matthey company for the loan of precious metal salts.

\section{REFERENCES}

1. P. S. Pregosin, P. G. A. Kumar, I. Fernandez. Chem. Rev. 105, 2977 (2005).

2. P. S. Pregosin. Prog. Nucl. Magn. Reson. Spectrosc. 49, 261 (2006).

3. E. Martinez-Viviente, H. Ruegger, P. S. Pregosin, J. Lopez-Serrano. Organometallics 21, 5841 (2002).

4. (a) K. Hayamizu, Y. Aihara, S. Arai, W. S. Price. Electrochim. Acta 45, 1313 (2000); (b) K. Hayamizu, E. Akiba, T. Bando, Y. Aihara, W. S. Price. Macromolecules 36, 2785 (2003).

5. I. Keresztes, P. G. Williard. J. Am. Chem. Soc. 122, 10228 (2000).

6. D. Nama, P. G. Anil Kumar, P. S. Pregosin. Magn. Reson. Chem. 43, 246 (2005).

7. (a) W. S. Price. Ann. Rep. NMR Spectrosc. 32, 51 (1996); (b) W. S. Price. Concepts Magn. Resonance 9, 299 (1997); (c) W. S. Price. Concepts Magn. Resonance 10, 197 (1998).

8. P. S. Pregosin, E. Martinez-Viviente, P. G. A. Kumar. Dalton Trans. 4007 (2003).

9. (a) D. Zuccaccia, A. Macchioni. Oranometallics 24, 3476 (2005); (b) C. Zuccaccia, N. G. Stahl, A. Macchioni, M. C. Chen, J. A. Roberts, T. J. Marks. J. Am. Chem. Soc. 126, 1448 (2004); (c) C. Zuccaccia, G. Bellachioma, G. Cardaci, A. Macchioni. Organometallics 19, 4663 (2000).

10. (a) Y. Wan, J. K. Angleson, A. G. Kutateladze. J. Am. Chem. Soc. 124, 5610 (2002); (b) M. Nilsson, I. F. Duarte, C. Almeida, I. Delgadillo, B. J. Goodfellow, A. M. Gil, G. A. Morris. J. Agric. Food Chem. 52, 3736 (2004); (c) R. M. Gschwind, X. L. Xie, P. R. Rajamohanan. Magn. Reson. Chem. 42, 308 (2004); (d) T. Evan-Salem, L. Frish, F. W. B. van Leeuwen, D. N. Reinhoudt, W. Verboom, M. S. Kaucher, J. T. Davis, Y. Cohen. Chem.—Eur. J 13, 1969 (2007).

11. (a) L. Avram, Y. Cohen. J. Am. Chem. Soc. 127, 5714 (2005); (b) Y. Cohen, L. Avram, L. Frish. Angew. Chem., Int. Ed. Engl. 44, 520 (2005).

12. I. Fernandez, E. Martinez-Viviente, P. S. Pregosin. Inorg. Chem. 43, 4555 (2004).

13. D. Schott, P. S. Pregosin, A. Albinati, S. Rizzato. Inorg. Chim. Acta 360, 3203 (2007). 
14. (a) E. Martinez-Viviente, P. S. Pregosin. Helv. Chim. Acta 86, 2364 (2003); (b) M. Alajarin, A. Pastor, R. A. Orenes, E. Martinez-Viviente, P. S. Pregosin. Chem.—Eur. J. 12, 877 (2006); (c) K. Shikii, H. Seki, S. Sakamoto, Y. Sei, H. Utsumi, K. Yamaguchi. Chem. Pharm. Bull. 53, 792 (2005); (d) E. J. Cabrita, S. Berger. Magn. Reson. Chem. 39, S142 (2001).

15. (a) K. Fagnou, M. Lautens. Angew. Chem., Int. Ed. 41, 27 (2002); (b) S. P. Smidt, N. Zimmermann, M. Studer, A. Pfaltz. Chem.-Eur. J. 10, 4685 (2004); (c) D. Semeril, C. Bruneau, P. H. Dixneuf. Adv. Synth. Catal. 344, 585 (2002).

16. (a) E. Martinez-Viviente, P. S. Pregosin. Inorg. Chem. 42, 2209 (2003); (b) I. Fernandez, E. Martinez-Viviente, P. S. Pregosin. Inorg. Chem. 44, 5509 (2005).

17. I. Fernández, E. Martínez-Viviente, F. Breher, P. S. Pregosin, Chem.-Eur. J. 11, 1495 (2005).

18. A. Moreno, P. S. Pregosin, L. F. Veiros, A. Albinati, S. Rizzato. Chem.-Eur. J. 14, 5617 (2008).

19. P. B. Hitchcock, A. V. Khvostov, M. F. Lappert, A. V. Protchenko. J. Organomet. Chem. 647, 198 (2002).

20. (a) A. Macchioni. Chem. Rev. 105, 2039 (2005); (b) D. Zuccaccia, S. Sabatini, G. Bellachiom, G. Cardaci, E. Clot, A. Macchioni. Inorg. Chem. 42, 5465 (2003); (c) A. Macchioni. Eur. J. Inorg. Chem. 195 (2003); (d) B. Binotti, A. Macchioni, C. Zuccaccia, D. Zuccaccia. Comments Inorg. Chem. 23, 417 (2002); (e) A. Burini, J. P. Fackler, R. Galassi, A. Macchioni, M. A. Omary, M. A. Rawashdeh-Omary, B. R. Pietroni, S. Sabatini, C. Zuccaccia. J. Am. Chem. Soc. 124, 4570 (2002).

21. D. Sirbu, G. Consiglio, B. Milani, P. G. A. Kumar, P. S. Pregosin, S. Gischig. J. Organomet. Chem. 690, 2254 (2005). The reader is recommended to consult the original literature for spectra, tables, and results from model complexes.

22. (a) E. P. Kundig, C. M. Saudan, F. Viton. Adv. Synth. Catal. 343, 51 (2001); (b) E. P. Kundig, M. C. Saudan, V. Alezra, F. Viton, G. Bernardinelli. Angew. Chem., Int. Ed. 40, 4481 (2001).

23. P. G. A. Kumar, P. S. Pregosin, M. Vallet, G. Bernardinelli, R. F. Jazzar, F. Viton, E. P. Kundig. Organometallics 23, 5410 (2004). The reader is recommended to consult the original literature for spectra, tables, and results from model complexes. 